\title{
Self-reported exposure to intimate partner violence among women and men in Sweden: results from a population-based survey
}

\author{
Lotta Nybergh ${ }^{1,2^{*}}$, Charles Taft ${ }^{3}$, Viveka Enander ${ }^{4,2}$ and Gunilla Krantz ${ }^{1,2}$
}

\begin{abstract}
Background: Few population-based studies assessing IPV among randomly selected women and men have been conducted in Sweden. Hence, the aim of the current study was to explore self-reported exposure, associated factors, social and behavioural consequences of and reasons given for using psychological, physical and sexual intimate partner violence (IPV) among women and men residing in Sweden.

Methods: Cross-sectional postal survey of women and men aged 18-65 years. Bivariate and multivariate logistic regression analyses were used to identify factors associated with exposure to IPV.

Results: Past-year IPV exposure rates were similar in women and men; however, earlier-in-life estimates were higher in women. Poor to moderate social support, growing up with domestic violence and being single, widowed or divorced were associated with exposure to all forms of IPV in men and women. Women and men tended to report different social consequences of IPV.

Conclusions: Our finding that women reported greater exposure to IPV earlier-in-life but not during the past year suggests the importance of taking this time frame into account when assessing gender differences in IPV. In-depth, qualitative studies that consider masculinities, femininities power and gender orders would be beneficial for extending and deepening our understanding of the gendered matter of IPV.
\end{abstract}

Keywords: Intimate partner violence, Sweden, WHO VAW instrument, Men, Women

\section{Background}

After continuous efforts from women's rights movements worldwide, violence against women has been recognized as a human rights violation [1] and public health problem of global magnitude [2]. There is now a considerable body of research on men's violence against female partners worldwide, as well as on its health consequences and associated factors [3]. Recently, men's victimization of intimate partner violence (IPV) has gained growing attention especially in high-income countries and there are a burgeoning number of studies assessing heterosexual IPV exposure among men [4-6].

\footnotetext{
* Correspondence: lotta.nybergh@socmed.gu.se

${ }^{1}$ Department of Public Health and Community Medicine, Institute of Medicine, The Sahlgrenska Academy at University of Gothenburg, Arvid Wallgrens Backe 7, PO Box 453, SE-405 30 Gothenburg, Sweden

${ }^{2}$ The Västra Götaland Region Competence Centre on Intimate Partner Violence, Kungsgatan 12, floor 6, 41119 Gothenburg, Sweden

Full list of author information is available at the end of the article
}

Some studies that have found similar levels of either exposure to or use of IPV among women and men have questioned the centrality and relevance of gender to the analysis of partner violence [7]. However, scholars have pointed out that even when the levels of violence may be similar, differences are found in the consequences, meaning, impact, context and ways in which gender is performed within a violent heterosexual relationship [8]. As such, the conceptualization of "gender" can be extended beyond the sex-difference of a particular violent act, to something that is actively "done" in everyday life in a way that shapes, confirms or challenges societal norms of masculinities and femininities. These norms, in turn, are informed by gender hierarchies and power [9] that may influence the experience, consequences and context in which IPV takes place $[10,11]$. 
Indeed the focus of most IPV research today has moved beyond considering the simple frequency of a violent act, and often considers other aspects of IPV, such as its severity, patterns, meaning, consequences and motivations [12]. Such studies show, for example, that men belittle women's use of physical violence against them and react to IPV with laughter and ridicule, [8,13] while women report greater fear of their partner [14] and feel less able to stop physically violent events than men [15]. Researchers have suggested that women's use of violence should be understood in the larger context of their ongoing victimization, [16] whereas men's use of violence often occurs in the context of coercive control [17]. Although contradictory research findings exist, [18] it is generally found that women experience more adverse physical [19] and mental [20] consequences, endure longer lasting violence, [21] more severe violence, [22] more coercive control, [5] more overlapping forms of violence, [4] stalking, [15] are less satisfied with their violent relationships and more likely to be victims of sexual violence than men $[4,5]$. Nonetheless, men who report IPV victimization have significantly poorer health and experience a range of negative psychosocial outcomes compared to men who do not report IPV [23]. Psychological violence is more rarely assessed than physical and sexual IPV in quantitative studies, and its definitions vary considerably. However, some studies find that it is more prevalent than physical or sexual IPV and that exposure rates are similar for men and women $[4,24,25]$. It has also been suggested that studies which find similar levels of IPV among women and men rely largely on past-year estimates or current partners, whereas studies assessing a longer time-frame or including previous partners tend to find dissimilar levels of violence [11]. Finally, it is noteworthy that important differences in IPV exposure exist within gender groups as well in relation to age, sexuality, ethnicity, (dis)abilities and other social categories [26].

Although many studies on IPV have been conducted in other countries, only one previous population-based study assessing IPV among randomly selected women and men has been conducted in Sweden [6]. That study used the Conflict Tactics Scale whereas the present study uses items from the World Health Organization's (WHO) Violence Against Women instrument (VAWI). The aim of the current study was to assess IPV exposure among adult women and men residing in Sweden. The specific aims were to explore self-reported 1) exposure to psychological, physical and sexual violence with regard to co-occurrence, prevalence and frequency during the past year and earlier in life by use of the VAWI; 2) sociodemographic and psychosocial factors associated with IPV; 3) social and behavioural consequences of IPV; 4) own use of violence and reasons given for using such violence by women and men.

\section{Methods}

\section{Sample}

A postal questionnaire was sent out through Statistics Sweden between January and March 2009 to a random national sample of 1006 women and 1009 men aged 1865 years and residing in Sweden. A total of 624 women (62.0\%) and 458 men (45.5\%) returned the questionnaire. Respondents with missing values on all the violence items (8.2\% women and $12.9 \%$ men) were excluded from the analyses, resulting in a total sample of 573 women and 399 men. The questionnaire included items on exposure to psychological, physical and sexual IPV, socio-demographic and psychosocial factors, own use of violence, reasons given for using violence and social and behavioural consequences of being exposed to violence.

\section{Comparisons between respondents and non-respondents}

Statistically significant differences between non-respondents and the final sample were assessed by using a twoproportion z-test with a Bonferroni adjustment to the alpha level. Variables included in the analysis were age, country of birth, civil status and individual annual income before tax.

A significantly larger proportion of the non-respondents ( $\mathrm{n}=382$ women and 551 men) were 18-29 years old, unmarried, foreign born and had a low annual income (0-159,999 Swedish crowns). A similar pattern was also found among those with missing values on all violence items $(\mathrm{n}=51$ women and 55 men), i.e. they were 18-29 years old, unmarried and had a low annual income as defined above.

\section{Measures \\ Intimate partner violence}

The WHO's Violence Against Women instrument (VAWI) assessing psychological (4 items), physical (6 items) and sexual (3 items) violence committed by an intimate partner was used [27]. The VAWI is, to the best of our knowledge, the only IPV instrument whose psychometric properties have been explored in a Swedish context among both women and men $[28,29]$. These studies were conducted on the same female and male samples as used in the current study. Support for the VAWI's construct validity and internal reliability among women has also been found by studies conducted in other countries [30-32]. For each question respondents were asked how often they had experienced a specific act during the past twelve months. Response options were 0 times, 1 time, 2 times, 3-5 times or $>5$ times. The response options of 1 and 2 times were combined into a single category. Respondents were also asked if they had experienced the violent act earlier in life. 
Table 1 Socio-demographic and psychosocial factors of the total sample, men and women

\begin{tabular}{|c|c|c|c|c|c|}
\hline \multirow[b]{2}{*}{ Characteristic } & \multicolumn{2}{|c|}{ Men N= 399} & \multicolumn{2}{|c|}{ Women $\mathrm{N}=573$} & \multirow[t]{2}{*}{ P-value* } \\
\hline & $\%$ & (N) & $\%$ & $(\mathrm{~N})$ & \\
\hline \multicolumn{6}{|l|}{ Age groups } \\
\hline $18-29$ & 14.3 & (57) & 18.7 & $(107)$ & .007 \\
\hline $30-39$ & 19.3 & (77) & 24.1 & (138) & \\
\hline $40-49$ & 24.1 & (96) & 21.8 & $(125)$ & \\
\hline $50-59$ & 24.6 & (98) & 23.7 & $(136)$ & \\
\hline $60-65$ & 17.8 & (71) & 11.7 & (67) & \\
\hline \multicolumn{6}{|l|}{ Civil status } \\
\hline Single/widowed/divorced & 12.1 & (48) & 14.9 & (85) & .325 \\
\hline Boyfriend/girlfriend & 13.4 & (53) & 11.2 & (64) & \\
\hline Married/cohabitant/registered partnership & 74.6 & (296) & 73.8 & $(420)$ & \\
\hline Heterosexual relationship & 86.2 & (344) & 83.2 & $(477)$ & \\
\hline Same-sex relationship & 1.3 & (5) & 1.2 & $(7)$ & \\
\hline \multicolumn{6}{|l|}{ Duration of the present relationship } \\
\hline$>10$ years & 56.9 & $(227)$ & 50.3 & (288) & .298 \\
\hline $4-10$ years & 15.5 & $(62)$ & 20.1 & $(115)$ & \\
\hline $1-3$ years & 16.0 & (64) & 14.3 & $(82)$ & \\
\hline \multicolumn{6}{|l|}{ Country of Birth } \\
\hline Sweden & 89.2 & $(356)$ & 90.6 & (519) & .164 \\
\hline Other Nordic country & 1.8 & $(7)$ & 2.6 & (15) & \\
\hline Other European country & 2.5 & (10) & 3.1 & (18) & \\
\hline Country outside of Europe & 6.5 & (26) & 3.7 & $(21)$ & \\
\hline \multicolumn{6}{|l|}{ Educational level (highest) } \\
\hline University & 39.4 & (156) & 47.2 & $(270)$ & .047 \\
\hline High school (10-12 yrs) & 43.7 & (173) & 36.9 & (211) & \\
\hline Compulsory ( $\leq 9 \mathrm{yrs}$ ) & 16.9 & (67) & 15.9 & (91) & \\
\hline \multicolumn{6}{|l|}{ Annual income (before tax, Swedish crowns) } \\
\hline 310,000 or more & 40.9 & $(163)$ & 15.2 & $(87)$ & .001 \\
\hline $235,000-309,999$ & 26.8 & $(107)$ & 25.0 & $(143)$ & \\
\hline $160,000-234,999$ & 13.0 & (52) & 30.5 & $(175)$ & \\
\hline $0-159,999$ & 19.3 & (77) & 29.3 & (168) & \\
\hline \multicolumn{6}{|l|}{ Employment status } \\
\hline Employed & 83.3 & (329) & 69.7 & (396) & $<0.0001$ \\
\hline Student & 5.1 & (20) & 6.2 & $(35)$ & \\
\hline Retired & 5.8 & (23) & 8.3 & $(47)$ & \\
\hline Sick leave (more than 3 months) & 1.3 & $(5)$ & 1.4 & (8) & \\
\hline Parental leave or leave of absence & 0.5 & $(2)$ & 6.2 & (35) & \\
\hline Unemployed & 2.8 & (11) & 4.0 & $(23)$ & \\
\hline Other & 1.3 & $(5)$ & 4.2 & $(24)$ & \\
\hline \multicolumn{6}{|l|}{ Access to social support } \\
\hline Yes & 64.4 & $(257)$ & 64.6 & (370) & .973 \\
\hline No & 11.8 & (47) & 10.5 & (60) & \\
\hline Unsure & 23.1 & (92) & 24.3 & (139) & \\
\hline
\end{tabular}


Table 1 Socio-demographic and psychosocial factors of the total sample, men and women (Continued)

\begin{tabular}{lcccc}
\hline Grown up in a home with violence between parents & & & & \\
No & 90.4 & $(357)$ & 90.3 & (510) \\
Yes & 9.4 & $(37)$ & 9.2 & (52) \\
Unsure & 0.3 & $(1)$ & 0.5 & (3) \\
\hline
\end{tabular}

*Mann Whitney $\mathrm{U}$ test for ordinal variables and Chi-squared test for independence for categorical variables.

\section{Dependent variables}

Psychological violence and a combined variable for physical and sexual violence (henceforth physical/sexual violence) were used as dichotomous outcome variables (unexposed vs. exposed to at least one act of violence) in the bivariate and multivariate logistic regression analyses. In order to increase statistical power, the past-year and earlier-inlife variables were merged into dichotomous life-time variables.

\section{Independent variables}

A range of socio-demographic and psychosocial variables were investigated. Social support was assessed by asking "At times one needs help and support from someone. Do you have a relative or friend who will help you when...", followed by four different situations where help and support might be needed: "...you get sick”, “...you need company", “...you need to speak to someone about personal concerns" and "...you need a loan over 15,000 Swedish crowns". An answer in the affirmative to all of the questions was coded good social support, whereas answering "no" or "unsure" to any of the questions was considered poor to moderate social support.

\section{Social and behavioural consequences of violence to everyday life, own use of violence and reasons for using such violence}

Respondents were asked whether they, as a consequence of having been exposed to IPV, had needed to make changes to their everyday lives in order to protect themselves. Furthermore, they were asked if they had used violence against their partner (yes/no), and if the respondent answered affirmatively, further questions inquired about which type of violence it was (psychological, physical or sexual) and reasons for using violence. Due to the exploratory nature of this study, a variety of closed questions followed by an open option for the consequences of violence and own use of violence were used. Results from the most frequently reported answers are given.

\section{Statistical analyses}

The Predictive Analytics SoftWare (PASW) statistical package version 19 and 20 were used and all analyses were conducted separately for women and men.
Differences in socio-demographic factors between women and men were checked for by the Chi-squared test for independence for all categorical variables (civil status, employment status, country of birth, access to social support and having grown up in a home with violence). The Mann Whitney $U$ test was used for the remaining ordinal variables. Differences between women's and men's responses to consequences of IPV and reasons for own use of violence were analyzed using the z-test for proportions. Fisher's exact probability test was used when a cell had less than 5 cases ( $\mathrm{p}$-value $<0.05$ ).

Bivariate analyses were performed between sociodemographic and psychosocial factors and exposure to lifetime psychological and physical/sexual violence. The analyses were repeated with dichotomized variables in order to increase statistical power for the multivariate analyses (not in Table). Statistically significant, dichotomized factors at the 0.05 significance level were included simultaneously in a multivariate logistic regression analysis to obtain adjusted odds ratios (OR) of the associations. Once a final model was obtained, those variables that had not met the inclusion criteria based on statistical significance were entered into the final model one at a time to see if they would contribute significantly to the model. Finally, theoretically relevant interaction terms were tested for significance. As duration of the present relationship and civil status correlated above 0.40 for women $(\mathrm{r}=.42)$ and men $(\mathrm{r}=.50)$, as did duration of the present relationship and age for men $(r=.55)$, duration of the present relationship was excluded from the multivariate analyses. Further multicollinearity could not be detected as the Tolerance value was above .40 and the Variance Inflation Factor was below 2.5 for all variables.

The co-occurrence of psychological, physical and sexual IPV was illustrated by Venn diagrams separately for the past-year and earlier-in-life time frames.

\section{Ethical considerations}

The study conformed with the WHO ethical and safety recommendations for research on domestic violence against women [33] and received ethical approval from the Regional Ethics Review Board in Gothenburg (Dnr: 527-08). Only one eligible person per household was chosen for ethical and safety reasons. Full anonymity and confidentiality were guaranteed and contact information for a general practitioner $(\mathrm{GK})$, a psychologist and a 
Table 2 Violence acts perpetrated by an intimate partner: past year (frequency) and earlier in life (yes/no)

\begin{tabular}{|c|c|c|c|c|c|c|c|c|c|c|}
\hline \multirow[b]{3}{*}{ Psychological violence } & \multicolumn{5}{|c|}{ Men: $\mathbf{N}=399$} & \multicolumn{5}{|c|}{ Women: $\mathrm{N}=573$} \\
\hline & \multicolumn{5}{|c|}{$\begin{array}{c}\text { Number of events, } \\
\text { past year \% a (N) }\end{array}$} & \multicolumn{5}{|c|}{$\begin{array}{l}\text { Number of events, } \\
\text { past year \% a (N) }\end{array}$} \\
\hline & Past year & $1-2$ & $3-5$ & $>5$ & Earlier in life & Past year & $1-2$ & $3-5$ & $>5$ & Earlier in life \\
\hline Insulted me in a way that made me feel bad & $20.5(79)$ & $13.2(51)$ & $2.1(8)$ & $5.2(20)$ & $12.0(48)$ & 20.7 (109) & $13.5(71)$ & $2.7(14)$ & $4.6(24)$ & $19.9(114)$ \\
\hline Belittled and humiliated me in front of others & $9.5(37)$ & $6.4(25)$ & $1.3(5)$ & $1.8(7)$ & $6.5(26)$ & $7.7(41)$ & $5.8(31)$ & $0.8(4)$ & $1.1(6)$ & $13.1(75)$ \\
\hline Tried to scare and terrorize me on purpose & $8.7(34)$ & $6.7(26)$ & $0.3(1)$ & $1.8(7)$ & $6.5(26)$ & $6.0(32)$ & $3.6(19)$ & $1.5(8)$ & $0.9(5)$ & $10.5(60)$ \\
\hline Threatened to hurt me or someone I care about & $1.0(4)$ & $0.3(1)$ & $0.3(1)$ & $0.5(2)$ & $2.8(11)$ & $1.5(8)$ & $0.7(4)$ & $0.4(2)$ & $0.4(2)$ & $7.3(42)$ \\
\hline Individuals exposed to acts of psychological violence & $24.0(92)$ & & & & $13.8(55)$ & $23.6(123)$ & & & & $23.6(135)$ \\
\hline Physical violence & Past year & $1-2$ & $3-5$ & $>5$ & Earlier in life & Past year & $1-2$ & $3-5$ & $>5$ & Earlier in life \\
\hline Pushed or shoved me & $5.9(23)$ & $4.6(18)$ & $0.3(1)$ & $1.0(4)$ & $5.3(21)$ & $7.1(38)$ & $5.5(29)$ & $0.9(5)$ & $0.8(4)$ & $2.6(72)$ \\
\hline Thrown something that could have hurt me & $2.8(11)$ & $2.3(9)$ & $0.3(1)$ & $0.3(1)$ & $3.3(13)$ & $1.7(9)$ & $1.3(7)$ & $0.2(1)$ & $0.2(1)$ & $5.1(29)$ \\
\hline Hit me with his/her fist or with some other object & $2.1(8)$ & $1.5(6)$ & $0.3(1)$ & $0.3(1)$ & $4.0(16)$ & $1.3(7)$ & $0.7(4)$ & - & $0.6(3)$ & $5.8(33)$ \\
\hline Kicked and dragged me and beaten me up & $0.8(3)$ & $0.3(1)$ & - & $0.5(2)$ & $1.5(6)$ & $0.6(3)$ & $0.2(1)$ & - & $0.4(2)$ & $3.5(20)$ \\
\hline Choked me or burnt me on purpose & $0.5(2)$ & $0.5(2)$ & - & - & $1.5(6)$ & $0.6(3)$ & $0.2(1)$ & $0.4(2)$ & - & $4.7(27)$ \\
\hline Hurt me with a knife, a gun or some other weapon & - & - & - & - & $1.5(6)$ & $0.2(1)$ & $0.2(1)$ & - & - & $1.2(7)$ \\
\hline Individuals exposed to acts of physical violence & $7.6(29)$ & & & & $6.8(27)$ & $8.1(43)$ & & & & $14.3(82)$ \\
\hline Sexual violence & Past year & $1-2$ & $3-5$ & $>5$ & Earlier in life & Past year & $1-2$ & $3-5$ & $>5$ & Earlier in life \\
\hline Demanded to have sex with me even though I did not want to & $2.3(9)$ & $1.8(7)$ & - & $0.5(2)$ & $2.3(9)$ & $2.6(14)$ & $1.5(8)$ & $0.4(2)$ & $0.7(4)$ & $8.2(47)$ \\
\hline Forced me to have sex against my will by using his/her physical strength & $0.3(1)$ & $0.3(1)$ & - & - & $1.3(5)$ & $0.4(2)$ & $0.2(1)$ & - & $0.2(1)$ & $2.6(15)$ \\
\hline Forced me to perform sexual acts that I experienced as degrading and/or humiliating & $0.3(1)$ & $0.3(1)$ & - & - & $1.8(7)$ & $0.4(2)$ & $0.4(2)$ & - & - & $4.2(24)$ \\
\hline Individuals exposed to acts of sexual violence & $2.3(9)$ & & & & $2.5(10)$ & $3.0(16)$ & & & & $9.2(53)$ \\
\hline Summary measures all forms of violence & $25.6(102)$ & & & & $15.3(61)$ & $23.2(133)$ & & & & $26.0(149)$ \\
\hline
\end{tabular}


contact person at Statistics Sweden was provided for additional information and/or referral.

\section{Results}

\section{Sample}

In comparison to women, men were older, had a lower level of education, were more often employed and had a higher annual income $(\mathrm{p}<0.05$; Table 1$)$. The majority of the sample was currently in a relationship $(85.1 \%$ women; $87.9 \%$ men) that was heterosexual (98.8\% women; $98.7 \%$ men) and had lasted over 10 years (59.4\% women; $64.3 \%$ men; Table 1).

\section{Prevalence, frequency and co-occurrence of} psychological, physical and sexual violence

IPV exposure rates during the past year were similar for women and men for all three forms of violence (Table 2). For example, $8.1 \%$ (95\% CI 5.9-10.3) of the women and $7.6 \%$ (95\% CI 5.0-10.2) of the men reported physical IPV. For earlier in life, women had higher exposure rates than men for all three forms of violence: psychological IPV was experienced by $23.6 \%$ (95\% CI 20.1-27.1) of the women and $13.8 \%$ (95\% CI 10.4-17.2) of the men; physical IPV by $14.3 \%$ (95\% CI 11.4-17.2) of the women and $6.8 \%$ (95\% CI 4.3-9.3) of the men; and sexual IPV by 9.2\% (95\% CI 6.8-11.6) of the women and 2.5\% (95\% CI 1.0-4.0) of the men. Most respondents were exposed to the first and comparatively less severe IPV item in each sub-scale and the frequency of exposure was generally 1-2 times during the past year (Table 2).

For both time frames, psychological violence alone was the most frequent form of violence, followed by a co-occurrence with physical violence (Figures 1 and 2). Although the patterns of co-occurrence were similar for women and men during the past year, differences were observed for the earlier-in-life time frame. For example, a greater proportion of women than men were simultaneously exposed to all three forms of IPV.

\section{Associated socio-demographic and psychosocial factors}

Factors associated with psychological IPV in the bivariate analyses were age, civil status, education, duration of the present relationship, social support and having grown up in a home with violence for both women and men (Table 3). Physical/sexual IPV was associated with civil status, duration of present relationship, social support and having grown up in a home with violence for both women and men. Moreover, age, income and partner's country of birth were associated with physical/sexual IPV for women (Table 4).

In the adjusted multivariate analyses for psychological and physical/sexual IPV, age for men and partner's country of birth for women no longer remained statistically significant (Table 5). Being single, widowed or divorced,

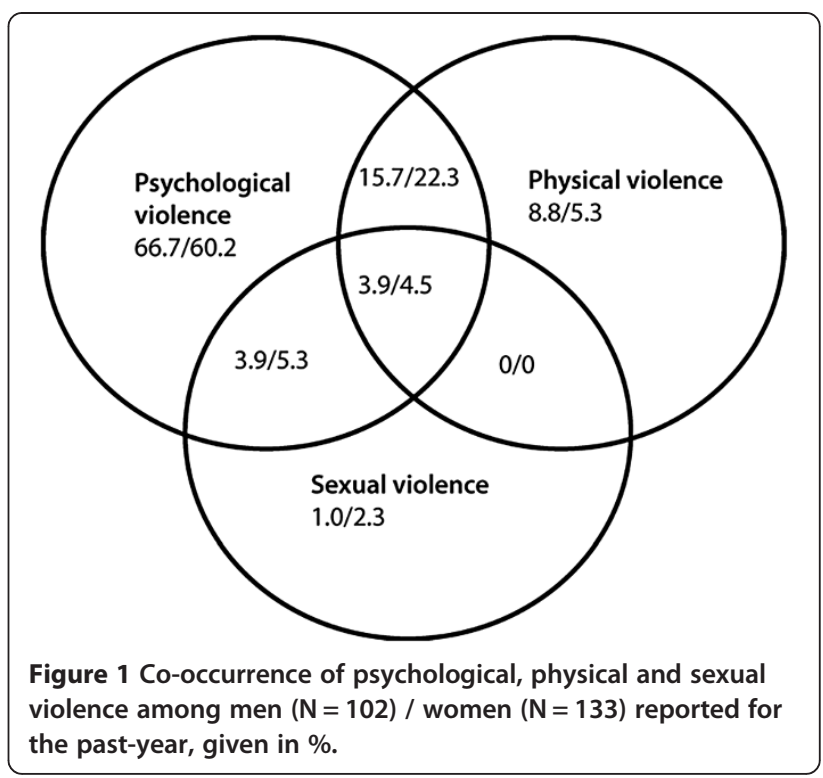

having poor/moderate access to social support and having grown up in a home with violence remained associated with exposure to psychological and physical/sexual IPV. Moreover, having a lower educational level decreased the likelihood of reporting psychological IPV for both women (OR 0.48; 95\% CI 0.27-0.83) and men (OR 0.45; 95\% CI 0.22-0.92). Entering the excluded variables one at a time showed no significant contribution to the final models and no significant interactions were found (analyses not shown).

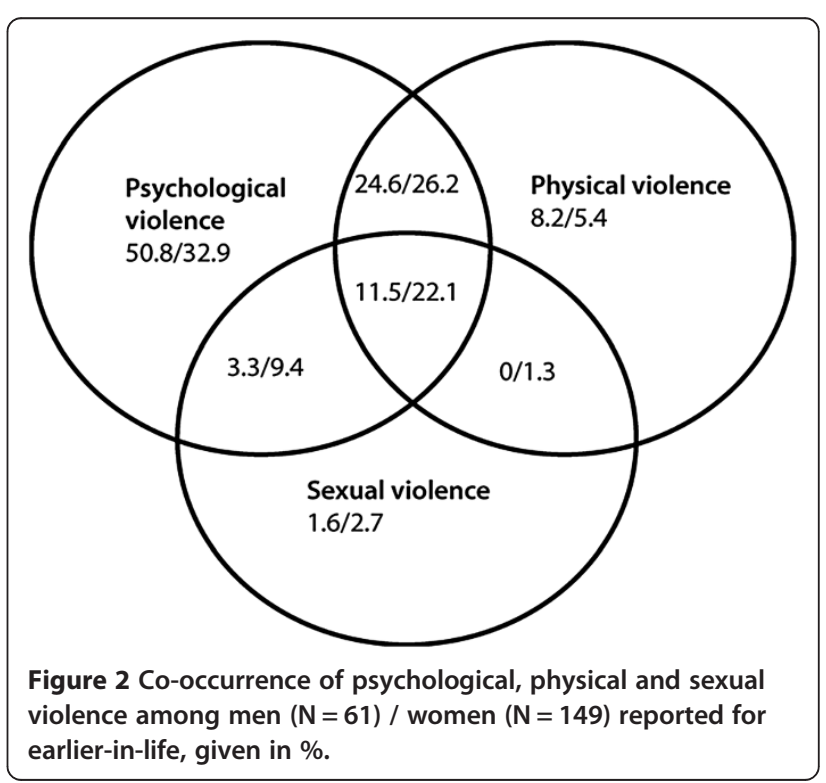


Table 3 Associations between psychological violence (life-time), socio-demographic and psychosocial factors

\begin{tabular}{|c|c|c|c|c|c|c|}
\hline & \multicolumn{6}{|c|}{ Psychological violence } \\
\hline & \multicolumn{3}{|c|}{ Men: $\mathrm{N}=399($ Exposed $\mathrm{N}=123)$} & \multicolumn{3}{|c|}{ Women: $\mathrm{N}=573($ Exposed $\mathrm{N}=212)$} \\
\hline & $\begin{array}{l}\text { Men } \\
\text { (N) }\end{array}$ & $\begin{array}{l}\text { Exposed } \\
\%(\mathrm{~N})\end{array}$ & $\begin{array}{l}\text { Crude OR } \\
(95 \% \mathrm{Cl})\end{array}$ & $\begin{array}{l}\text { Women } \\
(\mathrm{N})\end{array}$ & $\begin{array}{l}\text { Exposed } \\
\mathrm{N}(\%)\end{array}$ & $\begin{array}{l}\text { Crude OR } \\
(95 \% \mathrm{Cl})\end{array}$ \\
\hline \multicolumn{7}{|l|}{ Age groups } \\
\hline $60-65$ & 71 & $13.8(17)$ & 1 & 67 & $8.5(18)$ & 1 \\
\hline $50-59$ & 98 & $20.3(25)$ & $1.12(0.55-2.28)$ & 136 & $19.8(42)$ & $1.21(0.63-2.32)$ \\
\hline $40-49$ & 96 & $25.2(31)$ & $1.52(0.76-3.03)$ & 125 & $24.1(51)$ & $1.85(0.97-3.55)$ \\
\hline $30-39$ & 77 & $20.3(25)$ & $1.53(0.74-3.15)$ & 138 & $27.4(58)$ & $1.92(1.01-3.64)$ \\
\hline $18-29$ & 57 & $20.3(25)$ & $2.56(1.20-3.42)$ & 107 & $20.3(43)$ & $1.75(0.90-3.42)$ \\
\hline \multicolumn{7}{|l|}{ Civil Status } \\
\hline Married/cohabitant/registered partnership & 296 & $59.3(73)$ & 1 & 420 & $60.5(127)$ & 1 \\
\hline Boyfriend/girlfriend & 53 & $17.1(21)$ & $2.05(1.11-3.79)$ & 64 & $12.9(27)$ & $1.70(0.99-2.91)$ \\
\hline Single/widowed/divorced & 48 & $23.6(29)$ & $4.62(2.45-8.73)$ & 85 & $26.7(56)$ & $4.52(2.74-7.45)$ \\
\hline \multicolumn{7}{|l|}{ Duration of Present Relationship } \\
\hline$>10 \mathrm{yrs}$ & 227 & $45.9(45)$ & 1 & 288 & $48.1(76)$ & 1 \\
\hline $4-10$ yrs & 62 & $27.6(27)$ & $3.09(1.70-5.62)$ & 115 & $27.2(43)$ & $1.64(1.04-2.60)$ \\
\hline$\leq 3 \mathrm{yrs}$ & 34 & $26.5(26)$ & $2.81(1.55-5.11)$ & 82 & $24.7(39)$ & $2.46(1.48-4.08)$ \\
\hline \multicolumn{7}{|l|}{ Country of birth } \\
\hline Sweden & 356 & $90.2(110)$ & 1 & 517 & $91.5(193)$ & 1 \\
\hline Outside Sweden & 43 & $9.8(12)$ & $0.99(0.50-1.99)$ & 54 & $8.5(18)$ & $0.89(0.50-1.61)$ \\
\hline \multicolumn{7}{|l|}{ Partner's country of birth } \\
\hline Sweden & 349 & $84.6(104)$ & 1 & 494 & $83.5(177)$ & 1 \\
\hline Outside Sweden & 50 & $15.4(19)$ & $1.43(0.77-2.64)$ & 79 & $16.5(35)$ & $1.43(0.88-2.31)$ \\
\hline \multicolumn{7}{|l|}{ Educational level } \\
\hline University & 156 & $46.3(56)$ & 1 & 270 & $49.5(105)$ & 1 \\
\hline High school (10-12 yrs) & 173 & $43.0(52)$ & $0.64(0.39-1.03)$ & 211 & $38.7(82)$ & $0.96(0.67-1.40)$ \\
\hline Compulsory ( $\leq 9$ yrs) & 67 & $10.7(13)$ & $0.29(0.13-0.61)$ & 91 & $11.8(25)$ & $0.589(0.348-0.997)$ \\
\hline \multicolumn{7}{|l|}{ Annual Income (SEK) } \\
\hline 310,000 or more & 163 & $39.8(49)$ & 1 & 87 & $16.0(34)$ & 1 \\
\hline $235,000-309,999$ & 107 & $26.0(32)$ & $0.98(0.58-1.68)$ & 143 & $25.0(53)$ & $0.83(0.48-1.45)$ \\
\hline $160,000-234,999$ & 52 & $13.8(17)$ & $1.12(0.57-2.19)$ & 175 & $29.2(62)$ & $0.76(0.44-1.30)$ \\
\hline $0-159,999$ & 77 & $20.3(25)$ & $1.15(0.64-2.07)$ & 168 & $29.7(63)$ & $0.83(0.48-1.42)$ \\
\hline \multicolumn{7}{|l|}{ Employment status } \\
\hline Employed & 329 & $81.0(98)$ & 1 & 396 & $68.2(144)$ & 1 \\
\hline $\begin{array}{l}\text { Student, retired, sick-leave, parental leave or leave of absence, } \\
\text { unemployed, other }\end{array}$ & 66 & $19.0(23)$ & $1.24(0.71-2.18)$ & 172 & $31.8(67)$ & $1.11(0.77-1.61)$ \\
\hline \multicolumn{7}{|l|}{ Partner's employment status } \\
\hline Employed & 262 & $64.5(71)$ & 1 & 414 & $77.1(138)$ & 1 \\
\hline $\begin{array}{l}\text { Student, retired, sick-leave, parental leave or leave of absence, } \\
\text { unemployed, other }\end{array}$ & 121 & $35.5(39)$ & $1.28(0.80-2.05)$ & 111 & $22.9(41)$ & $1.14(0.74-1.77)$ \\
\hline \multicolumn{7}{|l|}{ Children living at home } \\
\hline No & 206 & $52.5(64)$ & 1 & 297 & $50.0(150)$ & 1 \\
\hline Yes & 190 & $47.5(58)$ & $0.97(0.63-1.47)$ & 270 & $50.0(105)$ & $1.17(0.83-1.65)$ \\
\hline
\end{tabular}


Table 3 Associations between psychological violence (life-time), socio-demographic and psychosocial factors (Continued)

\begin{tabular}{|c|c|c|c|c|c|c|}
\hline \multicolumn{7}{|c|}{ Access to social support } \\
\hline Good & 251 & $53.3(65)$ & 1 & 361 & $53.6(111)$ & 1 \\
\hline Poor/moderate & 139 & $46.7(57)$ & $1.97(1.27-3.06)$ & 199 & $46.4(96)$ & $2.06(1.44-2.95)$ \\
\hline \multicolumn{7}{|c|}{ Grown up in a home with violence } \\
\hline No & 357 & $83.5(101)$ & 1 & 510 & $82.5(170)$ & 1 \\
\hline Yes/Unsure & 38 & $16.5(20)$ & $2.78(1.41-5.48)$ & 55 & $17.5(36)$ & $3.92(2.16-7.10)$ \\
\hline
\end{tabular}

Total sample $\mathrm{n}=972$.

Social consequences of violence on everyday life, own use of violence and reasons for using such violence

In total, $10.1 \%(n=58)$ of the women and $6.5 \%(n=26)$ of the men experienced social consequences of having been exposed to IPV (Table 6). Only women reported consequences related to children, such as taking the children away from the home (20.7\% women vs. 0\% men), whereas men more frequently reported working more than usual to keep away from home (34.6\% men vs. $22.4 \%$ women). The differences between women's and men's responses were not statistically significant ( $p>0.05)$.

On the question of whether the respondent ever had used violence toward their intimate partner, $4.0 \%(n=23)$ of the women and $4.3 \%(n=17)$ of the men of the total sample answered in the affirmative. Out of these, the majority of women $(82.6 \% ; \mathrm{n}=19)$ and men $(82.4 \% ; \mathrm{n}=14)$ reported having both used and been exposed to IPV at some point in their lives. Finally, 2.1\% women and $2.0 \%$ men had used physical violence, $1.4 \%$ women and $1.8 \%$ men psychological violence and one woman had used sexual violence towards a male intimate partner (not in Table).

Reasons for using IPV were given by $9.6 \%(n=55)$ of the women and $8.0 \%(n=32)$ of the men in the total sample. The most common reason was having felt offended and/or hurt $(54.5 \%$ of the women and $50.0 \%$ of the men; Table 6). Other commonly reported reasons for using IPV included fear and self-defence $30.9 \%$ of the women and $18.8 \%$ of the men), alcohol or drug use $(16.4 \%$ of the women and $31.3 \%$ of the men) and loss of control (18.2\% of the women and $25.0 \%$ of the men). No statistically significant differences between women's and men's responses were observed.

\section{Discussion}

Although past-year exposure rates to psychological, physical and sexual IPV were similar among women and men, earlier-in-life exposure to all three forms of violence was significantly higher among women. Psychological, physical and sexual IPV often co-occurred. Factors associated with all forms of IPV for both women and men were poor/ moderate social support, having grown up in a home with violence and being single, divorced or widowed. There was a tendency for women and men to report different social consequences of IPV; however, these differences were not statistically significant.

Sweden is often considered to be one of the most gender equal countries worldwide with its high participation of both women and men in, for example, the labour force; decision-making posts, such as the Parliament; and higher education. There is generally a low tolerance of violence and using violence in an intimate relationship is punishable by law. There exist few studies that assess IPV in the general population of both women and men; the present findings confirm that IPV is common in Sweden and that continued efforts towards ending IPV are warranted. Professionals working within the health care sector should be sensitive towards the possibility that a male or female patient may have been exposed to violence in their intimate relationship and that this violence may take place in many different contexts and lead to a diverse set of consequences. Health professionals are in a unique and valuable position to detect and document IPV.

\section{Prevalence, frequency and co-occurrence of psychological, physical and sexual IPV}

Previous studies have also found that past-year IPV estimates are similar in women and men, but that earlier-in-life IPV is higher in women $[6,34,35]$. It may be hypothesized that the two different time frames in part reflect differences in severity and impact of IPV between women and men, which have been found by previous studies $[13,22]$. For example, considering that men generally experience less threatening and severe forms of IPV, they may not consider it particularly salient to remember later in life. Similarly, given that women are generally exposed to more severe forms of IPV with higher levels of physical injury, coercive control and fear, they may be more likely to report such violence also later in life [36]. Given that several studies rely on past-year estimates-which, for example, have been considered to be the norm in community-based samples [37]-this finding suggests that gender differences in exposure to IPV might go unnoticed if earlierin-life estimates are not accounted for. 
Table 4 Associations between physical/sexual violence (life-time), socio-demographic and psychosocial factors

\begin{tabular}{|c|c|c|c|c|c|c|}
\hline & \multicolumn{6}{|c|}{ Physical/sexual violence } \\
\hline & \multicolumn{3}{|c|}{ Men: $\mathrm{N}=399$ (Exposed $\mathrm{N}=56$ ) } & \multicolumn{3}{|c|}{ Women: $\mathrm{N}=573($ Exposed $\mathrm{N}=137)$} \\
\hline & $\begin{array}{l}\text { Men } \\
(\mathrm{N})\end{array}$ & $\begin{array}{c}\text { Exposed } \\
\%(\mathrm{~N})\end{array}$ & $\begin{array}{l}\text { Crude OR } \\
(95 \% \mathrm{Cl})\end{array}$ & $\begin{array}{l}\text { Women } \\
(\mathrm{N})\end{array}$ & $\begin{array}{l}\text { Exposed } \\
\%(\mathrm{~N})\end{array}$ & $\begin{array}{c}\text { Crude OR } \\
(95 \% \mathrm{Cl})\end{array}$ \\
\hline \multicolumn{7}{|l|}{ Age groups } \\
\hline $60-65$ & 71 & $16.1(9)$ & 1 & 67 & $5.8(8)$ & 1 \\
\hline $50-59$ & 98 & $14.3(8)$ & $0.62(0.23-1.69)$ & 136 & $17.5(24)$ & $1.63(0.69-3.86)$ \\
\hline $40-49$ & 96 & $30.4(17)$ & $1.52(0.63-3.64)$ & 125 & $23.4(32)$ & $2.48(1.07-5.75)$ \\
\hline $30-39$ & 77 & $14.3(8)$ & $0.81(0.29-2.23)$ & 138 & $29.2(40)$ & $2.94(1.29-6.72)$ \\
\hline $18-29$ & 57 & $25.0(14)$ & $2.26(0.90-5.70)$ & 107 & $24.1(33)$ & $3.22(1.38-7.51)$ \\
\hline \multicolumn{7}{|l|}{ Civil Status } \\
\hline Married/cohabitant/registered partnership & 296 & $58.9(33)$ & 1 & 420 & $56.6(77)$ & 1 \\
\hline Boyfriend/girlfriend & 53 & $14.3(8)$ & $1.43(0.62-3.29)$ & 64 & $15.4(21)$ & $2.28(1.27-4.07)$ \\
\hline Single/widowed/divorced & 48 & $26.8(15)$ & $4.06(1.97-8.35)$ & 85 & $27.9(38)$ & $4.44(2.66-7.42)$ \\
\hline \multicolumn{7}{|l|}{ Duration of Present Relationship } \\
\hline$>10$ yrs & 227 & $48.8(21)$ & 1 & 288 & $35.3(36)$ & 1 \\
\hline $4-10$ yrs & 62 & $23.3(10)$ & $1.91(0.85-4.30)$ & 115 & $31.4(32)$ & $2.71(1.58-4.64)$ \\
\hline$\leq 3 \mathrm{yrs}$ & 64 & $27.9(12)$ & $2.33(1.08-5.05)$ & 82 & $33.3(34)$ & $4.92(2.81-8.62)$ \\
\hline \multicolumn{7}{|l|}{ Country of birth } \\
\hline Sweden & 356 & $83.6(46)$ & 1 & 517 & $88.3(121)$ & 1 \\
\hline Outside Sweden & 43 & $16.4(9)$ & $187(0.84-4.18)$ & 54 & $11.7(16)$ & $1.34(0.72-2.49)$ \\
\hline \multicolumn{7}{|l|}{ Partner's country of birth } \\
\hline Sweden & 349 & $89.3(50)$ & 1 & 494 & $79.6(109)$ & 1 \\
\hline Outside Sweden & 50 & $10.7(6)$ & $0.88(0.36-2.19)$ & 79 & $20.4(28)$ & $1.92(1.15-3.20)$ \\
\hline \multicolumn{7}{|l|}{ Educational level } \\
\hline University & 156 & $48.1(26)$ & 1 & 270 & $48.2(66)$ & 1 \\
\hline High school (10-12 yrs) & 173 & $40.7(22)$ & $1.48(0.57-3.82)$ & 211 & $38.7(53)$ & $1.37(0.75-2.50)$ \\
\hline Compulsory ( $\leq 9$ yrs) & 67 & $11.1(6)$ & $2.10(0.82-5.37)$ & 91 & $13.1(18)$ & $1.31(0.73-2.35)$ \\
\hline \multicolumn{7}{|l|}{ Annual Income (SEK) } \\
\hline 310,000 or more & 163 & $32.1(18)$ & 1 & 87 & $8.8(12)$ & 1 \\
\hline 235,000-309,999 & 107 & $32.1(18)$ & $1.58(0.78-3.21)$ & 143 & $26.3(36)$ & $2.08(1.01-4.26)$ \\
\hline $160,000-234,999$ & 52 & $8.9(5)$ & $0.89(0.31-2.54)$ & 175 & $29.2(40)$ & $1.82(0.90-3.68)$ \\
\hline $0-159,999$ & 77 & $26.8(15)$ & $1.96(0.93-4.14)$ & 168 & $35.8(49)$ & $2.53(1.26-5.09)$ \\
\hline \multicolumn{7}{|l|}{ Employment status } \\
\hline Employed & 329 & $80.0(44)$ & 1 & 396 & $67.9(93)$ & 1 \\
\hline $\begin{array}{l}\text { Student, retired, sick-leave, parental leave or leave of absence, } \\
\text { unemployed, other }\end{array}$ & 66 & $20.0(11)$ & $1.31(0.64-2.79)$ & 172 & $32.1(44)$ & $1.13(0.74-1.71)$ \\
\hline \multicolumn{7}{|l|}{ Partner's employment status } \\
\hline Employed & 262 & $73.5(36)$ & 1 & 414 & $78.9(90)$ & 1 \\
\hline $\begin{array}{l}\text { Student, retired, sick-leave, parental leave or leave of absence, } \\
\text { unemployed, other }\end{array}$ & 121 & $26.5(13)$ & $0.78(0.40-1.53)$ & 111 & $21.1(24)$ & $0.99(0.60-1.65)$ \\
\hline \multicolumn{7}{|l|}{ Children living at home } \\
\hline No & 206 & $52.7(29)$ & 1 & 297 & $46.0(63)$ & 1 \\
\hline Yes & 190 & $47.3(26)$ & $0.98(0.55-1.73)$ & 270 & $54.0(74)$ & $1.36(0.93-2.01)$ \\
\hline
\end{tabular}


Table 4 Associations between physical/sexual violence (life-time), socio-demographic and psychosocial factors (Continued)

\begin{tabular}{|c|c|c|c|c|c|c|}
\hline \multicolumn{7}{|c|}{ Access to social support } \\
\hline Good & 251 & $44.6(25)$ & 1 & 361 & $47.4(64)$ & 1 \\
\hline Poor/moderate & 139 & $55.4(31)$ & $2.65(1.49-4.71)$ & 199 & $52.6(71)$ & $2.59(1.74-3.85)$ \\
\hline \multicolumn{7}{|c|}{ Grown up in a home with violence } \\
\hline No & 357 & $74.5(41)$ & 1 & 510 & $82.6(109)$ & 1 \\
\hline Yes/Unsure & 38 & $25.5(14)$ & $4.37(2.09-9.11)$ & 55 & 17. 4(23) & $3.09(1.70-5.60)$ \\
\hline
\end{tabular}

Total sample $n=972$.

Our past-year exposure rates are similar to those reported in previous studies, with the exception of sexual IPV, which is usually found to be more prevalent among women than men $[34,38]$. The earlier-in-life rates were somewhat lower in the current study compared to previous ones, $[34,39]$ which may be due to actual differences in prevalence and to differences in the definitions of IPV. In line with previous population-based studies, [40] severe acts of IPV were more seldom reported and our sample consisted mostly of the comparatively less severe acts of IPV.

The finding that women were exposed to all three forms of IPV more often than men within the earlier-in-life time frame $(22.1 \%$ vs. $11.5 \%)$ is supported by other studies [24]. However, corresponding rates during the past year were similar between women and men (4.5\% vs. $3.9 \%)$. This further highlights the importance of considering the earlier-in-life time frame when assessing gender differences in exposure to IPV. Our exposure rates for psychological violence are higher than the other forms of IPV, which is in line with previous studies $[4,24]$.
Finally, it is worth noting that while support has been found for the VAWI's validity among the female sample used in the current study, [29] the VAWI's conceptual model was only partially replicated among the male sample [28]. Instead, the boundaries between psychological, physical and sexual acts of violence were indistinct. Although further studies are needed in order to understand these results more fully, it nevertheless introduces a degree of uncertainty to our direct comparisons between women's and men's responses. Even if similar acts of violence are reported, the underlying constructs may differ. However, support for the instrument's reliability was found among both samples.

\section{Associated socio-demographic and psychosocial factors}

We found that both poor to moderate social support, having grown up in a home with violence and being single, widowed or divorced increased the likelihood of reporting exposure to psychological and physical/sexual IPV for both women and men residing in Sweden, which is in line with previous literature from other countries

Table 5 Adjusted associations between socio-demographic and psychosocial factors and exposure to psychological and physical/sexual violence

\begin{tabular}{|c|c|c|c|c|}
\hline & \multicolumn{2}{|c|}{ Psychological violence } & \multicolumn{2}{|c|}{ Physical/sexual violence } \\
\hline & Men: N = 399 & Women: $N=573$ & Men: N= 399 & Women: $\mathrm{N}=\mathbf{5 7 3}$ \\
\hline \multicolumn{5}{|l|}{ Civil status } \\
\hline $\begin{array}{l}\text { (Married/cohabitant/registered partnership/boy- or } \\
\text { girlfriend vs. Single/widowed/divorced) }\end{array}$ & $3.25(1.68-6.28)$ & $3.92(2.32-6.63)$ & $2.67(1.23-5.83)$ & $3.33(1.92-5.76)$ \\
\hline \multicolumn{5}{|l|}{ Access to social support } \\
\hline (Good vs. Poor/Moderate) & $2.03(1.27-3.25)$ & $2.12(1.44-3.12)$ & $2.62(1.42-4.83)$ & $2.52(1.66-3.84)$ \\
\hline \multicolumn{5}{|l|}{ Growing up in a home where violence occurred } \\
\hline (No vs. Yes/Unsure) & $2.47(1.19-5.13)$ & $3.09(1.62-5.88)$ & $4.03(1.84-8.83)$ & $2.15(1.18-4.14)$ \\
\hline \multicolumn{5}{|l|}{ Educational level } \\
\hline (Univ./High school vs. Compulsory) & $0.45(0.22-0.92)$ & $0.48(0.27-0.83)$ & - & - \\
\hline \multicolumn{5}{|l|}{ Age groups } \\
\hline (30-65 vs. $18-29)$ & $1.60(0.85-3.01)$ & - & $1.96(0.91-4.21)$ & - \\
\hline \multicolumn{5}{|l|}{ Partner's country of birth } \\
\hline (Sweden vs. outside Sweden) & - & - & - & $1.46(0.82-2.60)$ \\
\hline
\end{tabular}


Table 6 Social and behavioural consequences of IPV and reasons for using violence, \% (N)

\begin{tabular}{|c|c|c|}
\hline Number of respondents reporting social and behavioural consequences of IPV* & Men $\mathrm{N}=\mathbf{2 6}$ & Women $\mathrm{N}=58$ \\
\hline Work more than usual to keep away from home & $34.6(9)$ & $22.4(13)$ \\
\hline Keep distance to common friends & $15.4(4)$ & $24.1(14)$ \\
\hline Take the children away from the home & $0(0)$ & $20.7(12)$ \\
\hline Change work & $15.4(4)$ & $6.9(4)$ \\
\hline Avoid being at home when the children or no one else was at home & $0(0)$ & $6.9(4)$ \\
\hline Move away from home & $26.9(7)$ & $41.4(24)$ \\
\hline Divorce & $15.4(4)$ & $34.5(20)$ \\
\hline Live under a secret identity & $3.8(1)$ & $1.7(1)$ \\
\hline Number of respondents reporting reasons for using violence* & Men $\mathrm{N}=32$ & Women $\mathrm{N}=55$ \\
\hline I felt afraid and did it in self-defence in a violent situation & $18.8(6)$ & $30.9(17)$ \\
\hline I felt offended and/or hurt (saddened) & $50.0(16)$ & $54.5(30)$ \\
\hline I did it in a quarrel since my partner or we both had used alcohol or drugs & $31.3(10)$ & $16.4(9)$ \\
\hline I lost control & $25.0(8)$ & $18.2(10)$ \\
\hline
\end{tabular}

*Percentage is calculated based on those who responded to the question.

[24,41]. A possible explanation for the association between IPV and being single, widowed or divorced may be that the IPV was committed by a previous partner, which may be easier to report than violence experienced by a current partner.

Although most population-based studies investigate associated factors with physical and/or sexual IPV, our findings suggest that such factors are also associated with exposure to psychological IPV.

Educational level was also found to be associated with IPV, specifically having a university degree and/or having completed high school increased the likelihood for reporting psychological IPV for both men and women. Another population-based study assessing violence against men by several perpetrators and which was also conducted in Sweden has reported similar findings; [42] however, additional studies are needed to investigate this association further.

Social consequences of violence to everyday life, own use of violence and reasons for using such violence

\section{Social consequences}

Researchers have long underlined the importance of assessing consequences of IPV alongside the violent acts themselves as a way to consider the impact of IPV on women's and men's lives [35]. In the current study, a traditional gender structure emerged to some extent from the results: only women reported consequences which related to children, whereas men more often reported consequences related to work. As more women than men reacted by divorcing their spouse or moving away from home to protect themselves from IPV, a possible interpretation is that women felt more threatened by the violence and therefore took more measures to end the relationship than men. This finding is supported by a study where women were more likely to dissolve a heterosexual relationship than men if there occurred severe forms of violence, whereas women and men were equally likely to dissolve a relationship if there occurred less severe forms of IPV [43].

\section{Own use of violence}

Although only $4.0 \%$ women and $4.3 \%$ men in the total population sample reported having used IPV sometime in their lives when assessed by a single item, a larger number of the respondents ( $9.6 \%$ women and $8.0 \%$ men of the total sample), however, gave a reason for having used IPV. This discrepancy may not be surprising as respondents may find it easier to give reasons for using violence than to define their use of violence as IPV, which has indeed been found to under-estimate true prevalence rates [44]. Both women and men under-report their use of IPV although some studies have found women to under-report to a lesser extent than men [18]. Reasons for this may be that women are more prone to remember their use of violence as they are transgressing a gender norm in using violence, whereas the use of violence is a more acceptable part of masculinity constructions and therefore may go more unnoticed or become normalized [11]. Our finding that some report own use of violence may suggest that IPV takes place in several contexts, including relationships where the respondent is both exposed to and exposes his/her partner to violence, as shown by previous studies $[19,45]$.

\section{Reasons given for using violence}

Reasons given for perpetrating violent acts may also reflect on the context in which the IPV took place [35]. The most commonly self-reported reason for using IPV by both the women and men was having felt offended 
and/or hurt, which has also been reported in the literature [45]. The second most reported reason by women was feeling afraid and using violence in self-defence in a violent situation. Previous studies have often found women to use IPV in self-defence [46]. The second most reported reason by men for having used violence was in a quarrel in which alcohol or illicit drugs was involved.

\section{Methodological considerations}

The main known limitation of postal surveys is low response rates [47]. The current study included two reminders in an effort to minimize drop-out rates; however, the overall non-response rates were high for both women (38\%) and especially for men (54.6\%), which suggests caution in the interpretation of the results. The differing response rates among women and men also complicate the comparability of IPV between these two groups. Moreover, the response rates were lower among young, unmarried respondents, respondents with a lower annual income and respondents born outside Sweden. These groups have, especially among women [3], but also among men [48], been identified in the literature as particularly vulnerable to IPV. It is therefore possible that the current study has under-estimated the prevalence of IPV and consequently under-estimated the strengths of the associations between IPV and the socio-demographic factors. Also, an aggregate life-time variable was used to increase statistical power in the analyses assessing the associations between IPV and the socio-demographic factors. However, the exposure rates of IPV differed for women and men according to past-year and earlierin-life time frames and it is therefore possible that the associated factors would have differed for women and men had they been assessed separately for the two time-frames. Finally, as the study was cross-sectional, we are not able to draw any conclusions about cause and effect.

Furthermore, both women and men have been found to under-report their exposure to violence in heterosexual intimate partnerships, [18] although some studies have found that men may also over-report such exposure while at the same time being perpetrators of IPV [49]. Moreover, studies have found low to moderate inter-spousal agreement on the occurrence of IPV among heterosexual couples, both with regards to the frequency and the severity of the violence [18]. Additionally, the violent acts that the respondents have been exposed to may differ in context. As such, we are not able to differentiate between, for example, a shove made in self-defence and a shove made in a context of assault and intimidation [50]. As in all survey-based results relying on self-reports, caution should be used in interpreting the results.

Constructions of masculinity and femininity may influence how a person makes sense of and reports IPV, which in turn shapes results and conclusions $[8,11,18]$.
An important research question is thus whether men and women define and report IPV in different, gendered ways. Future studies on this topic would conceivably help in interpreting survey-based data.

\section{Conclusions}

The findings confirm that exposure to violent acts by an intimate partner is common in Sweden; however, the high non-response rates, especially among men, calls for careful interpretation of the results. Although past-year IPV exposure rates were similar in women and men, earlier-in-life exposure rates were higher in women. This suggests that the earlier-in-life time frame is important when assessing gender differences of IPV and future studies should consider it alongside past-year prevalence. Further in-depth, qualitative studies that probe deeper into the context of IPV in ways that consider masculinities, femininities, power and gender orders would contribute to a deeper understanding of the gendered matter of IPV.

\section{Competing interests}

The authors declare that they have no competing interests.

\section{Authors' contributions}

LN conducted all analyses, wrote the first draft of the manuscript and rewrote new drafts based on input from co-authors. CT and VE discussed and gave input on manuscript drafts. GK designed the project, planned the analyses and gave input on manuscript drafts. All authors read and approved the final manuscript.

\section{Acknowledgements}

The authors gratefully acknowledge the support of Valter Sundh and Björn Areskoug for their statistical advice.

\section{Funding}

This study was funded by a grant from the Swedish Research Council.

\section{Author details}

${ }^{1}$ Department of Public Health and Community Medicine, Institute of Medicine, The Sahlgrenska Academy at University of Gothenburg, Arvid Wallgrens Backe 7, PO Box 453, SE-405 30 Gothenburg, Sweden. ${ }^{2}$ The Västra Götaland Region Competence Centre on Intimate Partner Violence, Kungsgatan 12, floor 6, 41119 Gothenburg, Sweden. ${ }^{3}$ Institute of Health and Care Sciences, The University of Gothenburg Centre for Person-centred Care, The Sahlgrenska Academy at University of Gothenburg, Arvid Wallgrens Backe, PO Box 457, SE-405 30 Gothenburg, Sweden. ${ }^{4}$ Department of Social Work, University of Gothenburg, Sprängkullsgatan 23, PO Box 720, SE-405 30 Gothenburg, Sweden.

Received: 28 September 2012 Accepted: 5 September 2013 Published: 13 September 2013

\section{References}

1. Assembly UNG: Declaration on the elimination of violence against women. A/RES/48/104. New York: United Nations General Assembly (Assembly UNG); 1993.

2. Krug E, Mercy J, Dahlberg L, Zwi A: The world report on violence and health. Lancet 2002, 360:1083-1088.

3. Abramsky T, Watts C, Garcia-Moreno C, Devries K, Kiss L, Ellsberg M, Jansen H, Heise L: What factors are associated with recent intimate partner violence? Findings from the WHO multi-country study on women's health and domestic violence. BMC Publ Health 2011, 11:109.

4. Black MC, Basile KC, Breiding MJ, Smith SG, Walters ML, Merrick MT, Chen J, Stevens MR: The National Intimate Partner and Sexual Violence Survey (NISVS): 
2010 summary report. National Center for Injury Prevention and Control, Centers for Disease Control and Prevention: Atlanta, GA; 2011.

5. Coker AL, Davis KE, Arias I, Desai S, Sanderson M, Brandt HM, Smith PH: Physical and mental health effects of intimate partner violence for men and women. Am J Prev Med 2002, 23:260-268

6. Lövestad S, Krantz G: Men's and women's exposure and perpetration of partner violence: an epidemiological study from Sweden. BMC Publ Health 2012, 12:945.

7. Dixon L, Graham-Kevan N: Understanding the nature and etiology of intimate partner violence and implications for practice and policy: a review of the evidence. Clin Psychol Rev 2011, 31:1145-1155.

8. Dobash RP, Dobash RE: Women's violence to men in intimate relationships. Br J Criminol 2004, 44(3):324-349.

9. Connell RW: Masculinities. Berkley and Los Angeles, California: Univ of California Pr; 2005

10. Anderson $\mathrm{KL}$ : Theorizing gender in intimate partner violence research. Sex roles 2005, 52:853-865.

11. Kimmel MS: "Gender symmetry" in domestic violence: a substantive and methodological research review. Violence Against Women 2002, 8:1332-1363.

12. McHugh MC, Livingston NA, Ford A: A postmodern approach to women's use of violence: developing multiple and complex conceptualizations. Psychol Women Q 2005, 29:323-336.

13. Romito P, Grassi M: Does violence affect one gender more than the other? The mental health impact of violence among male and female university students. Soc Sci Med 2007, 65(6):1222-1234

14. Caldwell JE, Swan SC, Woodbrown VD: Gender differences in intimate partner violence outcomes. Psychol Viol 2012, 2(1):42.

15. Haaland T, Sten-Erik Clausen \& Berit Schei (red): Vold i parforhold-ulike perspektiver. Resultater fra den første landsdekkende undersøkelsen i Norge. (Couple violence-different perspectives. Results from the first national survey in Norway) NIBR-rapport 2005:3. Nordberg A.S.: Oslo; 2005.

16. Graham-Kevan N, Archer J: Investigating three explanations of women's relationship aggression. Psychol Women Q 2005, 29(3):270-277.

17. Stark E: Do violent acts equal abuse? Resolving the gender parity/ asymmetry dilemma. Sex Roles 2010, 62(3):201-211.

18. Chan KL: Gender differences in self-reports of intimate partner violence: a review. Aggress Violent Behav 2011, 16(2):167-175.

19. Straus MA: Dominance and symmetry in partner violence by male and female university students in 32 nations. Child Youth Serv Rev 2008, 30(3):252-275.

20. Schraiber LB, D'Oliveira AFPL, França I Jr: Intimate partner sexual violence among men and women in urban Brazil, 2005. Rev Saude Publica 2008, 42:127-137.

21. Tjaden $\mathrm{P}$, Thoennes $\mathrm{N}$ : Prevalence and consequences of male-to-female and female-to-male intimate partner violence as measured by the National Violence Against Women Survey. Violence Against Women 2000, 6:142-161

22. Randle AA, Graham CA: A review of the evidence on the effects of intimate partner violence on men. Psychol Men Masc 2011, 12:97-111.

23. Ansara DL, Hindin MJ: Psychosocial consequences of intimate partner violence for women and men in Canada. J Interpers Violence 2011, 26:1628-1645.

24. Romans S, Forte T, Cohen MM, Du Mont J, Hyman I: Who is most at risk for intimate partner violence? J Interpers Violence 2007, 22:1495-1514.

25. Outlaw M: No one type of intimate partner abuse: exploring physical and non-physical abuse among intimate partners. J Fam Violence 2009, 24:263-272.

26. Hester M, Donovan C: Researching domestic violence in same-sex relationships - a feminist epistemological approach to survey development. J Lesbian Stud 2009, 13:161-173.

27. WHO: Multi-country study on women's health and domestic violence against women. Initial results on prevalence, health outcomes and women's responses. Geneva: WHO/WHD; 2005.

28. Nybergh L, Taft C, Krantz G: Psychometric properties of the WHO Violence Against Women instrument in a male population-based sample in Sweden. BMJ Open 2012, 2. doi:10.1136/bmjopen-2012-002055.

29. Nybergh L, Taft C, Krantz G: Psychometric properties of the WHO Violence Against Women instrument in a female population-based sample in Sweden: a cross-sectional survey. BMJ open 2013, 3. doi:10.1136/bmjopen-2012-002053.

30. Schraiber L, Latorre M, França I Jr, Segri N, D'Oliveira A: Validity of the WHO VAW study instrument for estimating gender-based violence against women. Rev Saude Publica 2010, 44:658-666.
31. Garcia-Moreno C, Jansen HA, Ellsberg M, Heise L, Watts CH: Prevalence of intimate partner violence: findings from the WHO multi-country study on women's health and domestic violence. Lancet 2006, 368:1260-1269.

32. Saddki N, Sulaiman Z, Ali SH, Hassan TNFT, Abdullah S, Ab Rahman A, Ismail TAT, Jalil RA, Baharudin Z: Validity and reliability of the Malay version of WHO women's health and life experiences questionnaire. J Interpers Violence 2013, 28:2557-2580.

33. Watts $C$, Heise $L$, Ellsberg M, Moreno G: Putting women first: ethical and safety recommendations for research on domestic violence against women. Geneva: World Health Organization; 2001.

34. Heiskanen M, Ruuskanen E: Men's experiences of violence in Finland 2009. Helsinki: The European Institute for Crime Prevention and Control, affiliated with the United Nations (HEUNI); 2010.

35. Saunders DG: Are physical assaults by wives and girlfriends a major social problem? Violence Against Women 2002, 8:1424-1448.

36. Johnson MP: Conflict and control: gender symmetry and asymmetry in domestic violence. Violence Against Women 2006, 12:1003-1018.

37. Próspero M: Mental health symptoms among male victims of partner violence. Am J Mens Health 2007, 1:269-277.

38. Archer J: Sex differences in physically aggressive acts between heterosexual partners: a meta-analytic review. Aggress Violent Behav 2002, 7:313-351.

39. Piispa M, Heiskanen $M$, Kääriäinen J, Sirén R: Naisiin kohdistunut väkivalta 2005. (Violence against women in Finland 2005). National Research Institute of Legal Policy: Helsinki; 2006

40. Caetano R, Vaeth PAC, Ramisetty-Mikler S: Intimate partner violence victim and perpetrator characteristics among couples in the United States. J Fam Violence 2008, 23:507-518.

41. Jewkes R: Intimate partner violence: causes and prevention. Lancet 2002, 359:1423-1429.

42. Swahnberg K, Davidsson-Simmons J, Hearn J, Wijma B: Men's experiences of emotional, physical, and sexual abuse and abuse in health care: a cross-sectional study of a Swedish random male population sample. Scand J Public Health 2011, 40:191-202.

43. Anderson KL: Who gets out? Gender Soc 2007, 21:173-201.

44. Ellsberg M, Heise L, Peña R, Agurto S, Winkvist A: Researching domestic violence against women: methodological and ethical considerations. Stud Fam Plann 2001, 32:1-16.

45. Bair-Merritt MH, Shea Crowne S, Thompson DA, Sibinga E, Trent M, Campbell J: Why do women use intimate partner violence? a systematic review of women's motivations. Trauma Violence Abuse 2010, 11:178-189.

46. Swan SC, Gambone LJ, Caldwell JE, Sullivan TP, Snow DL: A review of research on women's use of violence with male intimate partners. Violence Vict 2008, 23:301-314.

47. Walby S: Improving the statistics on violence against women. Stat J UN Econ Comm Eur 2005, 22:193-216.

48. Breiding MJ, Black MC, Ryan GW: Prevalence and risk factors of intimate partner violence in eighteen US states/territories, 2005. Am J Prev Med 2008, 34:112-118.

49. Hester M: Who does what to whom? Gender and domestic violence perpetrators. Bristol: University of Bristol in association with the Northern Rock Foundation; 2009.

50. Osthoff S: But, Gertrude, I beg to differ, a hit is not a hit is not a hit. Violence Against Women 2002, 8:1521-1544.

\section{doi:10.1186/1471-2458-13-845}

Cite this article as: Nybergh et al.: Self-reported exposure to intimate partner violence among women and men in Sweden: results from a population-based survey. BMC Public Health 2013 13:845. 